\title{
The Role of Arbuscular Mycorrhiza Fungi in Drought Tolerance in Legume Crops: A Review
}

Yannan Hu, Arun K. Pandey, Xinyang Wu, Pingping Fang, Pei Xu

10.18805/LRF-660

\begin{abstract}
Legumes are low-cost but high-yielding crops, which are rich in dietary proteins, vitamins and minerals. Known as mycorrhizal plants, legumes are widely used as model organisms to explore the plant-microbe interactions, especially the symbiotic relationship between plants and rhizosphere microorganisms. Arbuscular mycorrhizal fungi (AMF), an important class of plant-associated microbes, can regulate many physiological and molecular responses of plants. To date, AMF has been commonly used as a bio-fertilizer, whose inoculation to host plants can confer tolerance to different abiotic stresses such as drought, salinity, heat and heavy metals. This review provides an overview of the responses of legumes to drought stress (DS), a summary of the mechanism of AMF-legume symbiosis and its effect on host plant drought tolerance, which taken together reveals the significance of this symbiosis in agriculture. The presented rich information will help understand how host plants benefit from AMF to increase drought tolerance while finetuning their metabolic pathways. The potential and importance of AMF as one of the most effective and environmental-friendly management approaches for enhancing legume crop productivity against DS is highlighted.
\end{abstract}

Key words: Abiotic factors, Arbuscular mycorrhizal fungi, Drought tolerance, Legume.

Abbreviations: AMF-Arbuscular mycorrhizal fungi; DS-Drought stress; ROS-Reactive oxygen species; CMN-Common mycorrhizal network; N-Nitrogen; P-Phosphorus; SOD-Superoxide dismutase; APX-Ascorbate peroxidase; GR-Glutathione reductase; IAA-Auxin; GA-Gibberellin; CTK-Cytokinin; ABA-Abscisic acid; JA-Jasmonic acid; AQPs-Aquaporins; LEA-Late embryogenesis abundant; PIPs-Plasma membrane aquaporins; TIPs-Tonoplast aquaporins.

Legumes, or pulse crops, are a valuable source of essential nutrients for the human diet because they contain essential amino acids and proteins as well as complex carbohydrates and dietary fiber (Kamboj and Nanda, 2017; Rubiales and Mikic, 2015). It has been demonstrated that pulse crops account for $12-15 \%$ of the global agricultural arable land area, contributing about $27 \%$ of the world's major food crops and $35 \%$ of the world's vegetable oil production (Mishra et al., 2014). Because of their agricultural importance and advantageous bioactive chemicals, legumes have been assigned economic, cultural, physiological and medical roles in addition to their nutritional quality (Graham and Vance, 2003). The consumption of legumes has also been reported to be associated with numerous beneficial health attributes (Mungai et al., 2016), such as hypocholesterolemic, antiatherogenic, anticarcinogenic and hypoglycemic properties (Ndidi et al., 2014).

Water shortage is one of the major limiting nonbiological factors that restrict the growth and development of global plants, including legumes (Jafarzadeh and Abbasi, 2006). Due to the lack of water, the cell shrinks, resulting in a reduction in cellular volume. As a result, the cellular substance becomes more viscous, causing protein denaturation (Hoekstra, 2001). When leguminous plants are excessively dehydrated, they exhibit a variety of negative responses at various stages, such as (i) reduction in the efficiency of solid $C$ (ii) osmotic stress (iii) induction of the production of reactive oxygen species (ROS) (Barzana et al., 2015). Plant-microbe interactions are known to be
Key Laboratory of Marine Food Quality and Hazard Controlling Technology of Zhejiang Province, Hangzhou 310018, China.

Corresponding Author: Pei $\mathrm{Xu}$, College of Life Sciences, China Jiliang University, Hangzhou 310018, China.

Email: peixu@cjlu.edu.cn

How to cite this article: Hu, Y., Pandey, A.K., Wu, X., Fang, P. and Xu, P. (2022). The Role of Arbuscular Mycorrhiza Fungi in Drought Tolerance in Legume Crops: A Review. Legume Research. 45(1): 1-9. DOI: 10.18805/LRF-660.

Submitted: 12-10-2021 Accepted: 04-12-2021 Online: 01-01-2022

ubiquitous and can be beneficial or harmful to the host or microbial parasites, depending on the balance of related biotic and abiotic stress. Legumes are widely used model organisms to understand the general law of this symbiotic relationship. Microorganisms related to plant growth may be located in the rhizosphere, leaf space or even inside the host plant (endophytes). Bacteria are able to be chemoattracted and move towards the root exudates released by the host plants, enabling them to colonize and multiply in the rhizosphere (Lugtenberg and Kamilova, 2009). It is currently well known that rhizosphere microorganisms play an important role in the growth of legumes. It is reported that mycorrhizas usually exist in roots of plants. So far, the research on arbuscular mycorrhizal fungi is far less than that of rhizobia.

The aim of this review is to summarize the interaction of arbuscular mycorrhizal fungi and legumes, the underlying 
mechanisms, as well as the significant practical significance of this symbiotic relationship in mitigating the adverse effects of drought.

\section{Effect of drought stress on legume crops}

Climate change, food shortage, water scarcity and population growth are some of the threatening challenges being faced in today's world. An increase in global temperature is accompanied by the intensification of drought stress, leading to the expansion of arid and semi-arid regions. Drought stress (DS) is a constant threat to crops and has been considered as the most important constraint to global agricultural productivity; its intensity and severity are predicted to increase in the near future. Due to this reason, the area suitable for the growth of legume crops is correspondingly reduced (Stephen Beebe, 2011). Among the various abiotic stresses, water deficit is the most important and uncontrollable factor. Grain legumes are extremely vulnerable to drought stress, which ultimately affects their grain production. Therefore, it is important to improve legumes for drought resilience. Drought affects the growth and development of legumes at various stages. The plant responses to drought stress vary between species and are affected by plant development stage and environmental conditions (Demirevska et al., 2009). Prolonged drought has adverse effects on many aspects such as seed germination, root and leaf development, photosynthetic efficiency, stoma control, flowering period and reproduction, which gives destructive effects during pod filling and hence affect the yield (Delmer, 2005; Pushpavalli et al., 2015). The germination rate in soybean (Liu et al., 2020) and chickpea (Nisha et al., 2019; Ruth Muruiki, 2018) was severely reduced due to water deficit, however, in faba bean, DS commonly occurs at the seedling stage and significantly affects yield (Li et al., 2018).

Photosynthesis is the vital pathway of energy metabolism of organisms, which has important biological significance for the growth and development of legumes. It is also reported that the water deficiency interfered with the activities of various enzymes related to carbon reactions in legumes, such as PPDK, PEPCase, EBPase and Rubisco, thereby inhibiting normal photosynthesis and ultimately reducing the net yield of grains and legumes (Farooq et al., 2014). Recent research results show that a certain degree of drought stress in soybean caused a decrease in net photosynthetic rate, the number of pods, the seed setting rate and the accumulation of dry matter, which ultimately reduced crop yields (Wang et al., 2018). Furthermore, the internal chlorophyll content and photosynthetic rate decreased significantly under drought, affecting their normal growth and development in broad beans (Siddiqui et al., 2015).

Drought also has an impact on the germination and growth of legume leaves. It was discovered in the 1980s that a lack of water promoted leaf senescence, the delay of the germination cycle of new leaves and the fall of old leaves (Karamanos, 1982). During the entire growth cycle of legumes, the flowering and reproduction periods are more susceptible to drought (Fang et al., 2010; Nezar et al., 2011). A certain intensity of drought stress shortened the flowering period and reduced the quantity and quality of nectar (Al-Ghzawi et al., 2009). At the same time, insufficient water may inhibit the germination of pollen grains and the growth of pollen tubes. In severe cases, drought led to infertility of pollen grains (Al-Ghzawi et al., 2009; Fang et al., 2010; Gusmao et al., 2012).

Studies have shown that water deficit also affects the nutrition and quality of crops, such as reducing the protein content in the grain (Singh, 2007). Furthermore, drought can also affect the content and composition of legume fatty acids (Bellaloui et al., 2013). It has been discovered that the severe drought had significantly reduced the oil and oleic acid content in soybeans (Shaheen et al., 2016). Drought hinders protein synthesis and promotes the content of free amino acids and hence ultimately affects the yield of cowpea (Mohammad Abass, 2016).

\section{Arbuscular mycorrhizal fungi and their agricultural and ecological importance}

\section{History and classification of AMF}

Arbuscular mycorrhizal fungi (AMF) are widely distributed in nature, which usually resides in the root cortex cells of the host and exist in the form of tiny branches (Bever et al., 2001). AMF-plant symbiosis has been documented to exist for at least 4 million years (Marc-André Selosse, 2015). AMF's symbiotic relationship is a classic example of a mutualistic relationship that can regulate plant growth and development. The theory of AMF's origin has been supported by a large of number fossil records, palaeobotanical data and phylogenetic analysis based on DNA sequences (James et al., 2006; Purahong et al., 2017). AMF can co-exist with nearly $80 \%$ of the roots of various types of plants on the planet and it can survive in high-stress conditions (Kivlin et al., 2011). A series of studies on various forms of Arbuscular were conducted at the beginning of the 20th century, which resulted in the classification of Arbuscular into two types: Paris and Arum (Smith, 1997). Currently, there are three forms of arbuscular structure: Arum, Paris and Intermediate. Mycorrhiza was originally proposed in 1885 , followed by arbuscules in 1905. The preliminary classification system was finally completed as AMF (Smith, 1997).

Endogone, Modicella and Glaziella are the three nonmycorrhizal genera, while Glomus, Sclerocystsis, Gigaspora and Acaulospora are the four mycorrhizal genera. A new mycorrhizal genus, Entrophospora, was identified by Trappe and Schenck (Gerdemann, 1974). Later, Walker added Scutellospora to the previous mycorrhizal classification and deleted Sclerocystsis (Tadros and Laarman, 1982). Morton and Benny split the aforementioned genera into three families, Glomaceae, Acaulosporaceae and Gigasporaceae, as well as two suborders, Glomineae and Gigasporaineae (Morton,1990). Later on, they further discovered two new families and two new genera, which are Archaeospora 
belonging to Archaeosporaceae and Paraglomus belonging to Paraglomaceae (Morton and Redecker, 2000). The AMF genus, however, is still being improved. Racocetra, Kuklospora, Pacispora, Otospora, Geosiphon, Ambispora and Intraspora are only a few of the novel genera found in recent years (Schüßler et al., 2001).

\section{Characteristics of AM symbiosis}

Arum and Paris are the two main arbuscular mycorrhizal symbionts and their characteristics are directly opposed. Paris-type fungi coexist with plants and the hyphae grow like coils inside the cells; however, the colonization of Arumtype fungi often involves the growth of hyphae longitudinally along the air channel between cortical cells through linear expansion. In other words, the Paris type develops from cells without intercellular phases and eventually forms the fungal circle. The biggest feature of the Arum type is the arbuscular branch (Dickson et al., 2007). The mycelial network of fungi spread under the roots of the plant and promotes nutrient uptake. The fungal mycelium colonises the roots of many plants, even those of different species, forming a common mycorrhizal network (CMN). This CMN is known as a major component of the terrestrial ecosystem due to its significant impact on various plant communities, particularly invasive plants (Pringle, 2009) and the fungal-mediated transport of nitrogen (N) and phosphorus (P) (Gilbert and Johnson, 2017).

\section{Agricultural and ecological importance of AMF}

It is reported that the AMF as a symbiotic fungus is found in about $90 \%$ of vascular plants and has a wide range of distribution (Gai et al., 2006; Redecker et al., 2013). This mutual symbiosis promotes the development of plant communities to increase yields (van der Heijden et al., 2008). The symbiosis of AMF and plants can not only promote nutrient absorption, enhance soil fertility and stabilize soil structure, but also improve water absorption efficiency and drought resistance. From a microbiological perspective, AMF mycelium helps parasitic plants to extend their roots. Compared with the plants without AMF, it is more likely to enter the deep soil and absorb more water (Adriana Marulanda, 2003; Bolandnazar et al., 2007; Khalvati et al., 2005; Ouledali et al., 2018; Pavithra and Yapa, 2018). When the environmental water is insufficient, the mycelium is destroyed and mycorrhizas, which are composed of many small and long hyphae, are connected to form a uniformly distributed absorption network, conferring more efficient water absorption than roots (de la Providencia et al., 2005).

\section{The mechanism of AMF-mediated drought resistance in legumes}

\section{General mechanisms of drought tolerance in legumes}

To mitigate the negative effects of drought, plants have developed various drought resistance mechanisms. In general, drought resistance can be divided into two categories: (i) the change of morphology and organization, which help obtain more water from the external environment and reduce water loss (Siddiqui et al., 2021); (ii) the synthesis of protective agents, regulators, or certain proteins and hormones, which alleviates the damage caused by drought and improves drought tolerance (Xing et al., 2016).

The length, width and the number of roots, among other structural properties of drought-tolerant plants, have been proposed as early as the end of the 1960s. For the growth and development of the plant, legumes' roots absorb water from the soil and transport it from the bottom up to the leaves through their root system. Therefore, longer roots are conducive to obtaining more water from the deep soil and enhancing its drought tolerance characteristics. Taking legumes as an example, when water is in short supply, the root system of drought-tolerant legumes is relatively long and the number of fibrous roots is relatively large (Sponchiado, 1989; Garay and Wilhelm, 1983; Farooq, 2009). For example, chickpeas with longer roots tend to be more drought tolerant and have higher yields (Deepa Jaganathan, 2015). However, on the other hand, when the environmental water is limited, the expansion of root angle reduces the penetration depth of the root system to a certain extent and increases the penetration range of the soil (Meister et al., 2014; Wasson et al., 2012). It is also reported that the depth of the root is usually determined by its diameter. The larger the diameter, the stronger the permeability and the greater the possibility of entering the deeper layers of the soil. Improving the drought tolerance of legumes is not only an increase in water absorption but also a reduction in water loss. When legumes are under drought conditions, a series of emergency physiological reactions occur, such as rapid closure of stomata, accompanied by a decrease in leaf area and solute accumulation (Agurla et al., 2018; Eremina et al., 2016; Shi et al., 2014).

From a metabolic point of view, the drought resistance mechanisms of legumes are usually divided into four categories, namely: drought escape, solute accumulation, antioxidant regulation and hormone regulation (Nadeem et al., 2019). First, drought escape is a common drought resistance mechanism. In a nutshell, the main response strategy for legumes is to reduce the growth period to adjust the water potential of plant tissues. The specific manifestation is to make full use of the limited soil moisture before the arrival of severe drought, to sustain yield (Farooq et al., 2014; Farooq et al., 2009). Whereas solute accumulation refers to some sugars or sugar alcohols produced by legumes in response to drought stress. Mannitol is a typical sugar alcohol that is utilized to scavenge free radicals and stabilize cell structure (Stoop et al., 1996). When legume crops are subjected to a particular level of drought stress, they release reactive oxygen species (ROS) and secrete several antioxidants and enzymes, including superoxide dismutase (SOD), ascorbate peroxidase (APX), glutathione reductase (GR), to name a few, to prevent the oxidative damage caused by excessive ROS (Saglam et al., 2011). In addition to producing antioxidants during growth and development, grain legumes also produce 
various hormones to regulate different functional pathways. Plant hormones such as auxin (IAA), gibberellin (GA), cytokinin (CTK), abscisic acid (ABA), ethylene and jasmonic acid (JA) are involved in the resistance to drought in legumes. Various results showed that ABA has played an important role in drought resistance: (i) the concentration of $A B A$ increases and the stomatal conductance decreases; (ii) ABA promotes root water absorption and transportation; (iii) $A B A$ enhances antioxidant enzyme activity and relieves a series of damages caused by oxidative stress (Merilo et al., 2015; Miyashita et al., 2005; Park et al., 2017).

At the molecular level, the drought resistance mechanism of legumes involves two well-characterized types of proteins, namely aquaporins (AQPs) and late embryogenesis abundant (LEA) proteins. AQPs were discovered as protein water channels on the cell or vacuole membrane (Park et al., 2017). Different types of AQPs have different functions. For example, plasma membrane aquaporins (PIPs) are mainly responsible for water absorption and transpiration, while tonoplast aquaporins (TIPs) are responsible for regulating the osmotic pressure of plants due to drought, ensuring cell viability (Fotiadis et al., 2001). When plants were challenged by drought, the activity of a significant number of AQPs decreases, resulting in increased water use efficiency and maintenance of the original water content in the tissue, which ultimately improves the plant's drought resistance. It is also proved that the expression level of AQPs is varying in different parts of plants. PIP1 and PIP2 expression levels are frequently higher in legume roots and leaves than in stems and PIP2 is more capable of transporting water (Luo et al., 2019). In the later stages of plant embryo development, another type of protein called LEA is abundant. LEA accumulates in large amounts when plants are under drought stress. LEA is supposed to serve an important role in binding water molecules and chelating ions, as well as maintaining the structure of other proteins and membranes (Sofi et al., 2018). Therefore, overexpression of LEA increases tolerance to osmotic stress (Sofi et al., 2018).

\section{Colonization of AMF in legumes}

The symbiosis between plants and rhizosphere bacteria is better understood than that between plants and AMF. A large number of studies have shown that rhizobia are natural symbiotic bacteria of legumes, colonizing them to form functional groups by promoting the nitrogen fixation of legumes and playing an important role in plant growth and development. However, the nutrients required for the growth of legumes include also a large amount of phosphorus and other elements (Almeida et al., 2000). Since the mycelium of AMF is the main place for the absorption and transportation of inorganic phosphorus, legumes often coexist with specific AMF. In fact, AMF has very low specificity for host plant selection, which exists in almost $80 \%$ of terrestrial plant roots. Most of the legumes species, such as M. sativa (Duan et al., 2011), M. truncatula (Mahmoudi et al., 2019), Lotus corniculatus
(Meghvansi et al., 2008) and P. vulgaris, have the ability to form symbiosis system with AMF.

AMF can be artificially colonized in the root nodules of legumes. Scheublin et al. (2004) conducted a phylogenetic analysis of AMF on six selected plants, three non-legumes (F. ovina, $P$. lanceolata and $H$. pilosella) and three legumes (L. corniculatus, Trifolium repens and Ononis repens) (Scheublin et al., 2004). Through phylogenetic analysis, the AMF sequences were classified into distinct groups. The result showed that the AMF had 28 group types, including a total of six families, of which Acaulosporaceae (14 families) and Glomeraceae (9 families) were the most numerous families. Experiments showed that the most common type of AMF sequence is from the specific group named Glo3 and the Glo8 were more common in nodules than in other parts of the roots. In addition, there may be a positive correlation between the content of Glo8 and the nitrogen concentration. For example, external application of nitrogen to plants can change the composition of the original AMF community (Eom et al., 2009).

Root nodules are the site where legumes fix nitrogen (Baird and Caruso, 1994). A total of 537 root nodules from three legumes (Trifolium repens L., Ononis repens L. and Lotus corniculatus L.) were studied for their nitrogen fixation activity and AMF colonization, in which up to $74 \%$ of the root nodules were found to contain AMF (Scheublin and van der Heijden, 2006). De Varennes and Goss (2007) explored the influence of AMF's customized frequency on arbuscular branches, hyphae and vesicles in the root of Medicago truncatula, which showed that under normal growth conditions, the colonization frequency of AMF in hyphae and arbuscular branches was as high as $65 \%$ and $42 \%$, respectively. Liu et al. (2009) studied the AMF of the legume species Caragana Korshinskii Kom in northwestern China and found that the average colonization rate of AMF in arbuscular branches and vesicles was $5.96 \%$ and $8.78 \%$, respectively.

\section{Mechanism of AMF-conferred water management in legumes}

The growth history of AM fungi involves four processes: (i) before infection; (ii) formation of hyphae between cells; (iii) formation of symbiotic structure; (iv) formation of free radical extra mycelia. In nature, AMF spontaneously parasitizes the rhizosphere of plants and the two interact to promote plant tolerance to various stresses, such as water deficit (Zhang et al., 2019). This beneficial symbiosis promotes the process of mycelium, including spore germination, hyphal differentiation, appressorium formation and other steps and finally forms mycelium, also called arbuscular structure, which promotes the exchange and absorption of nutrients and water (Goltapeh et al., 2008). Mycelium is the main structure of AMF, which can penetrate the outer cortex of roots, absorb various nutrients and water from the outside and finally transport to the host plant through the free radical hyphae in the root cells (Bonfante and Genre, 2010). Sieverding (1989) discovered that plant root length is positively correlated with the detected soil volume of the 
Table 1: AMF-conferred drought tolerance in legumes.

\begin{tabular}{|c|c|c|c|}
\hline Legume species & AMF species & Effect & Reference \\
\hline Common bean & $\begin{array}{l}\text { Glomus clarum } \\
\text { Acaulospora scrobiculata } \\
\text { Gigaspora rosea }\end{array}$ & $\begin{array}{l}\text { Increased root dry matter and root length density; } \\
\text { Increased the expression of the aquaporin PVPIP } 1 ; 1 \\
\text { gene; Diminished drastically the expression of the } \\
\text { PVPIP } 1 ; 2 \text { and } P V P I P 1 ; 3 \text { genes. }\end{array}$ & $\begin{array}{l}\text { (Aroca et al., 2007; } \\
\text { Recchia et al., 2018) }\end{array}$ \\
\hline Soybean & $\begin{array}{l}\text { Rhizophagus fasciculatus } \\
\text { Ambispora leptoticha }\end{array}$ & $\begin{array}{l}\text { Increased the TLA of the plant and thus the photosynthetic } \\
\text { activity and in turn; Increased the yield production; } \\
\text { Higher shoot dry biomass, root dry biomass and plant } \\
\text { dry biomass; Improved nutrient supply to plants, especially } \\
\text { in P deficient soils; Increased significantly the phosphorus } \\
\text { concentration of the plants. }\end{array}$ & $\begin{array}{l}\text { (Ashwin et al., 2019; } \\
\text { Mondal et al., 2017; } \\
\text { Rajan et al., 2005) }\end{array}$ \\
\hline Cowpea & $\begin{array}{l}\text { G. deserticola } \\
\text { G. gigantea }\end{array}$ & $\begin{array}{l}\text { Increased mineral elements uptake and improve water } \\
\text { relations; Increased the root hydraulic conductivity, } \\
\text { improved stomatalregulation, osmotic adjustment in } \\
\text { host and enabled extraction ofwater from smaller pores. }\end{array}$ & $\begin{array}{l}\text { (Augé, 2001; } \\
\text { Farahani et al., 2013; } \\
\text { Olawuyi et al., 2014) }\end{array}$ \\
\hline
\end{tabular}

plant body. Data showed that AMF mycelium transported about $46.2 \%$ of the water into the plant (Kakouridis et al., 2020). A similar study showed that when plants suffered drought, AMF hyphae was able to provide at least $1 / 5$ of the total water (McCorkle et al., 2011). In conclusion, through symbiosis, plants can develop beneficial mycelial structures in response to external stresses, enabling them to acquire more water and other nutrients.

The mycorrhizal plant response to drought can be divided into two mechanisms: mitigation and tolerance. The drought resistance of mycorrhizal plants usually causes morphological changes, such as the formation of an extensive hypha network, directly improving water absorption efficiency and indirectly maintaining the water-locking effect of plant leaves. When AMF colonizes at a certain plant, the water potential of the plant may decrease, forming a water potential difference with the external soil, which promotes water acquisition (Marulanda et al., 2003). In addition, AMF symbiosis can also bring a series of indirect benefits to drought parasitic plants. For example, AMF promotes the production of polysaccharides, mannitol and other substances in plants, which can be closely combined with soil particles, promoting the formation of soil aggregates, optimizing soil structure and improving soil moisture retention (Singh et al., 2013).

Taking leguminous plants as an example, first of all, AMF inoculation on mungbean's roots can mitigate the negative impact on plants due to soil water shortage by adjusting the tissue water potentials (Habibzadeh et al., 2014). A study has documented that AMF can produce a glycoprotein to form soil aggregates to optimize soil structure and achieve the best effect of water retention in legumes (Amorpha canescens Pursh, Lespedeza capitata Michx, Lupinus perennis L., Dalea candida Michx and Dalea purpurea Vent) (Burrows, 2014). Porcel and Ruiz-lozano (2004) found that AMF inoculation can increase the level of osmoprotectants to improve the tolerance of soybean to drought stress (Porcel and Ruiz-Lozano, 2004). In Table 1, a collection of literature reporting on the AMF-conferred drought tolerance in various legumes is presented.

\section{Interaction between AMF and other beneficial soil microorganisms}

The rhizosphere is an extremely complex environment. In simple terms, it is the interface between the plant and the root. Roots are the key organ for the symbiosis between plants and microorganisms, which includes rhizobia and AMF to help absorb water and nutrients (Gao et al., 2019). The main function of AMF includes absorbing phosphorus. It is found that the content and absorption of $P$ in the buds of mycorrhizal plants are higher than those of nonmycorrhizal plants (Yao et al., 2001). Microorganisms in the roots of legumes with root nodule symbiosis and arbuscular mycorrhizal symbiosis can interact with each other (O'Brian et al., 2009). This interaction can affect the rhizosphere structure and improve the activity of soil microorganisms, thus making the plants more easily obtain organic and nonpolar nutrients. In addition, some researchers conducted field research and reported that the strains inoculated with rhizobia and AMF can produce more nodules and have a higher AMF infection rate than those inoculated with rhizobia or AMF alone (Marques et al., 2001). Therefore, the study of the interaction between legumes and soil microorganisms, especially the interaction between nitrogen-fixing bacteria and AMF, is important (Marzban et al., 2017). Studies have suggested that the colonization of rhizobia requires a high level of phosphorus, while AMF has the function of helping phosphorus absorption (Smith and Read, 2008). There is hence no wonder that the roots of legumes can simultaneously colonize AMF and nitrogen-fixing bacteria.

\section{CONCLUSION AND FutuRE RESEARCH PERSPECTIVES}

Drought stress has posed grand challenge to agriculture all around the world. The symbiosis of microorganisms, a microbiological approach, has been a useful tool to tackle 
this challenge. Compared with physical, chemical and other biological measures, the microbiological method is nondestructive, effective and cost-saving. While AMF was initially considered as beneficial entities for nutrient uptake from the soil, it has recently been demonstrated to effectively combat various environmental cues, such as salinity, drought, nutrient stress, alkali stress, cold and extreme temperatures, thus helping increase the yield of a wide range of crops and vegetables (Pavithra and Yapa, 2018). At present, the beneficial rhizosphere microbial inoculants have become popularized in agricultural practices for many crops beyond the legumes. However, there may also be unfavorable relationships between different types of rhizosphere microorganisms, such as competition and antagonism. Certain types of indigenous microorganisms in the soil may have adverse reactions with externally applied microorganisms, which is counterproductive (Romdhane et al., 2021). The primary focus of future research should be on the identification of genes controlling the AMF-mediated growth and development regulation under stressful conditions, both host plant and AMF specific genes that regulate symbiotic relationship, as well as the important cellular and metabolic processes under different environmental conditions. A better understanding of the AMF-induced modulations in drought tolerance and the crosstalk triggered to regulate plant performance can help improve crop productivity.

\section{ACKNOWLEDGEMENT}

This study was partially supported by the Natural Science Foundation of Zhejiang Province (LQ21C150004), the fund of Hubei Engineering Research Center for Protection and Utilization of Special Biological Resources in the Hanjiang River Basin (Grant No. 2021-01) and the Key Research Program of Zhejiang Province (2021C02041).

\section{REFERENCES}

Adriana Marulanda, R.A., Ruiz-Lozano, J.M. (2003). Contribution of six arbuscular mycorrhizal fungal isolates to water uptake by Lactuca sativa plants under drought stress. Physiologia Plantarum. 119(4): 526-533.

Agurla, S., Gahir, S., Munemasa, S., Murata, Y. and Raghavendra, A.S. (2018). Mechanism of stomatal closure in plants exposed to drought and cold stress. Advances in Experimental Medicine and Biology. 1081: 215-232.

Al-Ghzawi, A.A.M., Zaitoun, S., Gosheh, H. and Alqudah, A. (2009). Impacts of drought on pollination of Trigonella moabitica (Fabaceae) via bee visitations. Archives of Agronomy and Soil Science. 55(6): 683-692.

Almeida, J., Hartwig, U., Frehner, M., Nösberger, J. and Lüscher, A. (2000). Evidence that $P$ deficiency induces $N$ feedback regulation of symbiotic $\mathrm{N}_{2}$ fixation in white clover (Trifolium repens L.). Journal of Experimental Botany. 51: 1289-1297.

Aroca, R., Porcel, R. and Ruiz-Lozano, J.M. (2007). How does arbuscular mycorrhizal symbiosis regulate root hydraulic properties and plasma membrane aquaporins in Phaseolus vulgaris under drought, cold or salinity stresses? The New Phytologist. 173(4): 808-816.
Ashwin, R., Bagyaraj, D.J. and Mohan Raju, B. (2019). Symbiotic response of drought tolerant soybean varieties, DSR 2 and DSR 12 to different Arbuscular mycorrhizal fungi. Proceedings of the National Academy of Sciences, India Section B: Biological Sciences. 89(2): 649-655.

Augé, R.M. (2001). Water relations, drought and vesicular-arbuscular mycorrhizal symbiosis. Mycorrhiza. 11(1): 3-42.

Baird, L. and Caruso, K. (1994). Development of root nodules in phaseolus vulgaris inoculated with rhizobium and mycorrhizal fungi. International Journal of Plant Sciences. 155(6). https://doi.org/10.1086/297203.

Barzana, G., Aroca, R. and Ruiz-Lozano, J.M. (2015). Localized and non-localized effects of arbuscular mycorrhizal symbiosis on accumulation of osmolytes and aquaporins and on antioxidant systems in maize plants subjected to total or partial root drying. Plant Cell and Environment. 38(8): 1613-1627.

Bellaloui, N., Mengistu, A. and Kassem, M.A. (2013). Effects of genetics and environment on fatty acid stability in soybean seed. Food and Nutrition Sciences. 4(9): 165-175.

Bever, J.D., Schultz, P.A., Pringle, A. and Morton, J.B. (2001). Arbuscular Mycorrhizal Fungi: more diverse than meets the eye and the ecological tale of why. BioScience. 51(11): 923-931.

Bolandnazar, S., Aliasgarzad, N., Neishabury, M.R. and Chaparzadeh, N. (2007). Mycorrhizal colonization improves onion (Allium cepa L.) yield and water use efficiency under water deficit condition. Scientia Horticulturae. 114(1): 11-15.

Bonfante, P. and Genre, A. (2010). Mechanisms underlying beneficial plant-fungus interactions in mycorrhizal symbiosis. Nature Communications. 1: 48.

Burrows, R. (2014). Glomalin production and infectivity of arbuscularmycorrhizal fungi in response to grassland plant diversity. American Journal of Plant Sciences. 5(1): 103-111.

De la Providencia, I.E., de Souza, F.A., Fernandez, F., Delmas, N.S. and Declerck, S. (2005). Arbuscular mycorrhizal fungi reveal distinct patterns of anastomosis formation and hyphal healing mechanisms between different phylogenic groups. New Phytol. 165(1): 261-271.

Deepa Jaganathan, M.T., Kale, S., Azam, S., Roorkiwal, M., Gaur, P.M., Kavi Kishor, P.B., Nguyen, H., Sutton T. and Varshney, R.K. (2015). Genotyping-by-sequencing based intra-specific genetic map refines a "QTL-hotspot" region for drought tolerance in chickpea. Molecular Genetics and Genomics. 290: 559-571.

Delmer, D.P. (2005). Agriculture in the developing world Connecting innovations in plant research to downstream applications. Biotechnology and Developing World. 102(44): 1573915746.

Demirevska, K., Zasheva, D., Dimitrov, R., Simova-Stoilova, L., Stamenova, M. et al. (2009). Drought stress effects on Rubisco in wheat: Changes in the Rubisco large subunit. Acta Physiologiae Plantarum. 31(6): 1129-1138.

De Varennes, A. and Goss, M.J. (2007). The tripartite symbiosis between legumes, rhizobia and indigenous mycorrhizal fungi is more efficient in undisturbed soil. Soil Biology and Biochemistry. 39(10): 2603-2607.

Dickson, S., Smith, F.A. and Smith, S.E. (2007). Structural differences in arbuscular mycorrhizal symbioses: more than 100 years after Gallaud, where next? Mycorrhiza. 17(5): 375-393. 
Duan, T., Facelli, E., Smith, S.E., Smith, F.A. and Nan, Z. (2011). Differential effects of soil disturbance and plant residue retention on function of arbuscular mycorrhizal (AM) symbiosis are not reflected in colonization of roots or hyphal development in soil. Soil Biology and Biochemistry. 43(3): $571-578$.

Eom, A.H., Hartnett, D., Wilson, G. and Figge, D. (2009). The effect of fire, mowing and fertilizer amendment on arbuscular mycorrhizas in tallgrass prairie. The American Midland Naturalist. 142: 55-70.

Eremina, M., Rozhon, W. and Poppenberger, B. (2016). Hormonal control of cold stress responses in plants. Cellular and Molecular Life Science. 73(4): 797-810.

Fang, X., Turner, N.C., Yan, G., Li, F. and Siddique, K.H. (2010). Flower numbers, pod production, pollen viability and pistil function are reduced and flower and pod abortion increased in chickpea (Cicer arietinum L.) under terminal drought. Journal of Experimental Botany. 61(2): 335-345.

Farahani, A.S., Lebaschi, H., Hussein, M.A.A., Hussein., S.A., Reza, V.A., et al. (2013). Effects of arbuscular mycorrhizal fungi, different levels of phosphorus and drought stress on water use efficiency, relative water content and proline accumulation rate of coriander (Coriandrum sativum L.). Journal of Medicinal Plants Research. 2: 125-131.

Farooq, M., Hussain, M. and Siddique, K.H.M. (2014). Drought stress in wheat during flowering and grain-filling periods. Critical Reviews in Plant Sciences. 33(4): 331-349.

Farooq, M., Wahid, A., Kobayashi, N., Fujita, D. and Basra, S.M.A. (2009). Plant drought stress: Effects, mechanisms and management. Agronomy for Sustainable Development. 29(1): 185-212.

Fotiadis, D., Jenö, P., Mini, T., Wirtz, S., Müller, S.A., et al. (2001). Structural characterization of two aquaporins isolated from native spinach leaf plasma membranes. Journal of Biological Chemistry. 276(3): 1707-1714.

Gai, J.P., Christie, P., Feng, G. and Li, X.L. (2006). Twenty years of research on community composition and species distribution of arbuscular mycorrhizal fungi in China: A review. Mycorrhiza. 16(4): 229-239.

Gao, F.L., Che, X.X., Yu, F.H. and Li, J.M. (2019). Cascading effects of nitrogen, rhizobia and parasitism via a host plant. Flora. 251: $62-67$.

Garay, A.F. and Wilhelm, W.W. (1983). Root system characteristics of two soybean isolines undergoing water stress conditions. Agronomy Journal. 75(6): 973-977.

Gerdemann, J.W. and Trappe, J.M. (1974). Endogonaceae in the pacific northwest. Mycologia Memoir. 5: 1-76.

Gilbert, L. and Johnson, D. (2017). Plant-Plant Communication through Common Mycorrhizal Networks. In: How Plants Communicate with their Biotic Environment. Advances in Botanical Research. (pp. 83-97).

Goltapeh, E., Rezaee Danesh, Y., Prasad, R. and Varma, A. (2008). Mycorrhizal Fungi: What We Know and What Should We Know? In: Mycorrhiza. [Varma A. (eds)], Springer, Berlin, Heidelberg. Mycorrhiza (pp. 3-27).

Graham, P.H. and Vance, C.P. (2003). Legumes: importance and constraints to greater use. Plant Physiology. 131(3): 872-877.
Gusmao, M., Siddique, K.H.M., Flower, K., Nesbitt, H. and Veneklaas, E.J. (2012). Water deficit during the reproductive period of grass pea (Lathyrus sativus L.) reduced grain yield but maintained seed size. Journal of Agronomy and Crop Science. 198(6): 430-441.

Habibzadeh, Y., Eivazi, A. and Abedi, M. (2014). Alleviation drought stress of mungbean (Vigna radiata L.) plants by using arbuscular mycorrhizal fungi. International Journal of Agricultural Sciences and Natural Resources. 1(1): 1-6.

Hoekstra, F. A., Golovina, E.A. and Buitink, J. (2001). Mechanisms of plant desiccation tolerance. Trends in Plant Science. 6(9): 431-438.

Jafarzadeh, A.A. and Abbasi, G. (2006). Qualitative land suitability evaluation for the growth of onion, potato, maize and alfalfa on soils of the Khalat pushan research station. Biologia. 61(S19): S349-S352.

James, T.Y., Kauff, F., Schoch, C.L., Matheny, P.B., Hofstetter, V., et al. (2006). Reconstructing the early evolution of fungi using a six-gene phylogeny. Nature. 443(7113): 818-822.

Kakouridis, A., Hagen, J.A., Kan, M.P., Mambelli, S., Feldman, L.J., et al. (2020). Routes to roots: Direct evidence of water transport by arbuscular mycorrhizal fungi to host plants. bioRxiv. doi:10.1101/2020.09.21.305409.

Kamboj, R. and Nanda, V. (2017). Proximate composition, nutritional profile and health benefits of legumes- A review. Legume Research. 41(3): 325-332.

Karamanos, A.J., Elston, J. and Wadsworth, R.M. (1982). Water stress and leaf growth of field beans (Vicia faba L.) in the field water potentials and laminar expansion. Annals of Botany. 49(6): 815-826.

Khalvati, M.A., Hu, Y., Mozafar, A. and Schmidhalter, U. (2005). Quantification of water uptake by arbuscular mycorrhizal hyphae and its significance for leaf growth, water relations and gas exchange of barley subjected to drought stress. Plant Biology. 7(6): 706-712.

Kivlin, S.N., Hawkes, C.V. and Treseder, K.K. (2011). Global diversity and distribution of arbuscular mycorrhizal fungi. Soil Biology and Biochemistry. 43(11): 2294-2303.

Li, P., Zhang, Y., Wu, X. and Liu, Y. (2018). Drought stress impact on leaf proteome variations of faba bean (Vicia faba L.) in the Qinghai-Tibet Plateau of China. 3 Biotech. 8(2): 110.

Liu, Y., He, L., An, L., Helgason, T. and Feng, H. (2009). Arbuscular mycorrhizal dynamics in a chronosequence of Caragana korshinskii plantations. FEMS Microbiology Ecology. 67(1): 81-92.

Liu, Z., Li, H., Gou, Z., Zhang, Y., Wang, X., et al. (2020). Genomewide association study of soybean seed germination under drought stress. Molecular Genetics and Genomics. 295(3): 661-673.

Lugtenberg, B. and Kamilova, F. (2009). Plant-growth-promoting rhizobacteria. Annual Review of Microbiology. 63: 541-556.

Luo, L., Xia, H. and Lu, B.R. (2019). Editorial: Crop breeding for drought resistance. Frontiers in Plant Science. 10: 314.

Mahmoudi, N., Cruz, C., Mahdhi, M., Mars, M. and Caeiro, M.F. (2019). Arbuscular mycorrhizal fungi in soil, roots and rhizosphere of Medicago truncatula: Diversity and heterogeneity under semi-arid conditions. Peer J. 7: e6401. 
Marques, M., Pagano, M. and Scotti, M. R. (2001). Dual inoculation of a woody legume (Centrolobium tomentosum) with rhizobia and mycorrhizal fungi in south-eastern Brazil. Agroforestry Systems. 50: 107-117.

Marulanda, A., Azcón, R. and Ruiz-Lozano, J. (2003). Contribution of six arbuscular mycorrhizal fungal isolates to water uptake by Lactuca sativa plants under drought stress. Physiologia Plantarum. 119: 526-533.

Marzban, Z., Faryabi, E. and Torabian, S. (2017). Effects of arbuscular mycorrhizal fungi and Rhizobium on ion content and root characteristics of green bean and maize under intercropping. Acta Agriculturae Slovenica. 109(1): 79-88.

McCorkle, R., Ercolano, E., Lazenby, M., Schulman-Green, D., Schilling, L.S., et al. (2011). Self-management: Enabling and empowering patients living with cancer as a chronic illness. CA-A Cancer Journal for Clinicians. 61(1): 50-62.

Meghvansi, M. K., Prasad, K., Harwani, D. and Mahna, S.K. (2008). Response of soybean cultivars toward inoculation with three arbuscular mycorrhizal fungi and Bradyrhizobium japonicum in the alluvial soil. European Journal of Soil Biology. 44(3): 316-323.

Meister, R., Rajani, M.S., Ruzicka, D. and Schachtman, D.P. (2014). Challenges of modifying root traits in crops for agriculture. Trends in Plant Science. 19(12): 779-788.

Merilo, E., Jalakas, P., Laanemets, K., Mohammadi, O., Hõrak, H., et al. (2015). Abscisic scid transport and homeostasis in the context of stomatal regulation. Molecular Plant. 8(9): 1321-1333.

Mishra, S., Panda, S.K. and Sahoo, L. (2014). Transgenic asiatic grain legumes for salt tolerance and functional genomics. Reviews in Agricultural Science. 2(0): 21-36.

Miyashita, K., Tanakamaru, S., Maitani, T. and Kimura, K. (2005). Recovery responses of photosynthesis, transpiration and stomatal conductance in kidney bean following drought stress. Environmental and Experimental Botany. 53(2): 205-214.

Mohammad Abass., Narges Moradtalab., Elsayed Fathi Abd-Allah., Parvaiz Ahmad and Roghieh Hajiboland. (2016). Plant growth under drought stress: Significance of mineral nutrients. Water Stress and Crop Plants: A Sustainable Approach. 2: 649-668.

Mondal, T., Datta, J.K. and Mondal, N.K. (2017). Chemical fertilizer in conjunction with biofertilizer and vermicompost induced changes in morpho-physiological and bio-chemical traits of mustard crop. Journal of the Saudi Society of Agricultural Sciences. 16(2): 135-144.

Morton, J.B. and Redecker, D. (2000). Two new families of Glomales, Archaeosporaceae and Paraglomaceae, with two new genera Archaeospora and Paraglomus, based on concordant molecular and morphological characters. Mycologia. 93(1): 181-195.

Morton, J.B., Benny, G. L. (1990). Revised classification of arbuscular mycorrhizal fungi (Zygomycetes): A new order, Glomales, two new suborders, Glomineae and Gigasporineae and two new families, Acaulosporaceae and Gigasporaceae, with an emendation of Glomaceae. Mycotaxon. 37: 471-491.

Mungai, L.M., Snapp, S., Messina, J.P., Chikowo, R., Smith, A., et al. (2016). Smallholder farms and the potential for sustainable intensification. Frontiers in Plant Science, 7: 1720.
Nadeem, M., Li, J., Yahya, M., Sher, A., Ma, C., et al. (2019). Research progress and perspective on drought stress in legumes: A review. International Journal of Molecular Sciences. 20(10): 2541.

Ndidi, U.S., Ndidi, C.U., Aimola, I.A., Bassa, O.Y., Mankilik, M., et al. (2014). Effects of processing (boiling and roasting) on the nutritional and antinutritional properties of bambara groundnuts [Vigna subterranea (L.) Verdc.] from Southern Kaduna, Nigeria. Journal of Food Processing. 2014: 1-9.

Nezar, S., Haddad, N., Alqudah, A.M. (2011). Yield potential evaluation in chickpea genotypes under late terminal drought in relation to the length of reproductive stage. Italian Journal of Agronomy. 4(3): 111-117.

Nisha, Walia, M., Batra, N., Gera, R. and Goyal, S. (2019). Impact of management practices on soil microbial properties under wheat-cluster bean cropping system. Legume Research. 42(4): 565-571.

O'Brian, M.R., Vance, C.P. and Vandenbosch, K.A. (2009). Legume focus: Model species sequenced, mutagenesis approaches extended and debut of a new model. Plant Physiology. 151(3): 969.

Olawuyi, O.J., Odebode, Olakojo, S., Popoola, A., Akanmu, A., et al. (2014). Host-pathogen interaction of maize (Zea mays L.) and Aspergillus niger as influenced by arbuscular mycorrhizal fungi (Glomus deserticola). Archives of Agronomy and Soil Science. 60(11): 1577-1591.

Ouledali, S., Ennajeh, M., Zrig, A., Gianinazzi, S. and Khemira, H. (2018). Estimating the contribution of arbuscular mycorrhizal fungi to drought tolerance of potted olive trees (Olea europaea). Acta Physiologiae Plantarum. 40(5): 81.

Park, J., Lee, Y., Martinoia, E. and Geisler, M. (2017). Plant hormone transporters: What we know and what we would like to know. BMC Biology. 15(1): 93.

Pavithra, D. and Yapa, N. (2018). Arbuscular mycorrhizal fungi inoculation enhances drought stress tolerance of plants. Groundwater for Sustainable Development. 7: 490-494.

Porcel, R. and Ruiz-Lozano, J. (2004). Arbuscular mycorrhizal influence on leaf water potential, solute accumulation and oxidative stress in soybean plants subjected to drought stress. Journal of Experimental Botany. 55: 1743-1750.

Pringle, A. (2009). Mycorrhizal networks. Current Biology. 19(18): R838-R839.

Purahong, W., Wubet, T., Kruger, D. and Buscot, F. (2017). Molecular evidence strongly supports deadwood-inhabiting fungi exhibiting unexpected tree species preferences in temperate forests. ISME Journal. 12: 289-295.

Pushpavalli, R., Zaman-Allah, M., Turner, N.C., Baddam, R., Rao, M.V. et al. (2015). Higher flower and seed number leads to higher yield under water stress conditions imposed during reproduction in chickpea. Functional Plant Biology. 42(2): 162-174.

Rajan, S., Bagyaraj, D. and Arpana, J. (2005). Sreening for an efficient arbuscular mycorrhizal fungi for inoculating Albizzia lebbeck. Soil Biology and Biochemistry. 25: 110-115.

Recchia, G.H., Konzen, E.R., Cassieri, F., Caldas, D.G.G. and Tsai, S.M. (2018). Arbuscular mycorrhizal symbiosis leads to differential regulation of drought-responsive genes in tissue-specific root cells of common bean. Frontiers in Microbiology. 9: 1339. 
Redecker, D., Schussler, A., Stockinger, H., Sturmer, S.L., Morton, J.B., et al. (2013). An evidence-based consensus for the classification of arbuscular mycorrhizal fungi (Glomeromycota). Mycorrhiza. 23(7): 515-531.

Romdhane, S., Spor, A., Aubert, J., Bru, D., Breuil, M.C., et al. (2021). Unraveling negative biotic interactions determining soil microbial community assembly and functioning. The ISME Journal. In press. https://doi.org/10.1038/s41396-02101076-9.

Rubiales, D. and Mikic, A. (2015). Introduction: Legumes in sustainable agriculture. Critical Reviews in Plant Sciences. 34:1-3.

Ruth Muruiki, P.K., Vincent, V., Rao, G., Said, S. and Moses, S. (2018). Effect of drought stress on yield performance of parental chickpea genotypes in semi-arid Tropics. Journal of Life Sciences. 12(3): 159-168.

Saglam, A., Saruhan, N., Terzi, R. and Kadioglu, A. (2011). The relations between antioxidant enzymes and chlorophyll fluorescence parameters in common bean cultivars differing in sensitivity to drought stress. Russian Journal of Plant Physiology. 58(1): 60-68.

Scheublin, T.R. and van der Heijden, M.G. (2006). Arbuscular mycorrhizal fungi colonize nonfixing root nodules of several legume species. New Phytologist. 172(4): 732-738.

Scheublin, T., Ridgway, K., Young, J.P. and Van der Heijden, M. (2004). Nonlegumes, legumes and root nodules harbor different arbuscular mycorrhizal fungal communities. Applied and Environmental Microbiology. 70(10): 6240-6246.

Schüßler, A., Schwarzott, D. and Walker, C. (2001). A new fungal phylum, the Glomeromycota: Phylogeny and evolution. Mycological Research. 105(12): 1413-1421.

Selmar, D. and Kleinwachter, M. (2013). Stress enhances the synthesis of secondary plant products: The impact of stress-related over-reduction on the accumulation of natural products. Plant and Cell Physiology. 54(6): 817-826.

Selosse, M.A., Strullu-Derrien, C., Martin, F.M., Kamoun, S. and Kenrick, P. (2015). Plants, fungi and oomycetes a 400million year affair that shapes the biosphere. The New Phytologist. 206(2): 501-506.

Shaheen, T., Rahman, M.U., Shahid Riaz, M., Zafar, Y. and Rahman, M.U. (2016). 8-soybean production and drought stress. Abiotic and Biotic Stresses in Soybean Production. 1: 177-196.

Shi, H., Ye, T., Zhu, J. K. and Chan, Z. (2014). Constitutive production of nitric oxide leads to enhanced drought stress resistance and extensive transcriptional reprogramming in Arabidopsis. Journal of Experimental Botany. 65(15): 4119-4131.

Siddiqui, M.H., Al-Khaishany, M.Y., Al-Qutami, M.A., Al-Whaibi, M.H., Grover, A., et al. (2015). Response of different genotypes of faba bean plant to drought stress. International Journal of Molecular Science. 16(5): 10214-10227.

Siddiqui, M.N., Léon, J., Naz, A.A. and Ballvora, A. (2021). Genetics and genomics of root system variation in adaptation to drought stress in cereal crops. Journal of Experimental Botany. 72(4): 1007-1019.

Singh, P.K., Singh, M. and Tripathi, B.N. (2013). Glomalin: An arbuscular mycorrhizal fungal soil protein. Protoplasma. 250(3): 663-669.
Singh, S.P. (2007). Drought resistance in the race durango dry bean landraces and cultivars. Agronomy Journal. 99(5): 1219-1225.

Smith, F.A. and Smith, S.E. (1997). Tansley review No. 96 structural diversity in (vesicular)- arbuscular mycorrhizal symbioses. New Phytologist. 137: 373-388.

Smith, S.E. and Read, D.J. (2008). Mycorrhizal Symbiosis, $3^{\text {rd }}$ edn. Academic Press, London.

Sofi, P., Maduraimuthu, D., Siddique, K. and Prasad, P.V.V. (2018). Reproductive fitness in common bean (Phaseolus vulgaris L.) under drought stress is associated with root length and volume. Indian Journal of Plant Physiology. 23(4). DOI:10.1007/s40502-018-0429-x.

Sponchiado, B.N., White, J.W., Castillo, J.A. and Jones, P.G. (1989). Root growth of four common bean cultivars in relation to drought tolerance in environments with contrasting soil types. Experimental Agriculture. 25(2): 249-257.

Stephen Beebe, J.R., Jarvis, A., Rao, I.M., Mosquera, G., Bueno, J.M. and Blair, M.W. (2011). Genetic Improvement of Common Beans and the Challenges of Climate Change. In: Crop Adaptation to Climate Change, John Wiley and Sons, Inc, Oxford (GB): 356-369.

Stoop, J.M.H., Williamson, J.D. and Mason Pharr, D. (1996). Mannitol metabolism in plants: A method for coping with stress. Trends in Plant Science. 1(5): 139-144.

Tadros, W. and Laarman, J.J. (1982). Current concepts on the biology, evolution and taxonomy of tissue cyst-forming eimeriid coccidia. Advances in Parasitology. 20: 293-468.

van der Heijden, M.G., Bardgett, R.D. and van Straalen, N.M. (2008). The unseen majority: Soil microbes as drivers of plant diversity and productivity in terrestrial ecosystems. Ecology Letters.11(3): 296-310.

Wang, W., Wang, C., Pan, D., Zhang, Y., Luo, B., et al. (2018). Effects of drought stress on photosynthesis and chlorophyll fluorescence images of soybean (Glycine max) seedlings. International Journal of Agricultural and Biological Engineering. 11(2): 196-201.

Wasson, A.P., Richards, R.A., Chatrath, R., Misra, S.C., Prasad, S.V. et al. (2012). Traits and selection strategies to improve root systems and water uptake in water-limited wheat crops. Journal of Experimental Botany. 63(9): 3485-3498.

Xing, X., Jiang, H., Zhou, Q., Xing, H., Jiang, H., et al. (2016). Improved drought tolerance by early IAA- and ABAdependent $\mathrm{H}_{2} \mathrm{O}_{2}$ accumulation induced by $\alpha$-naphthaleneacetic acid in soybean plants. Plant Growth Regulation. 80(3): 303-314.

Yao, Q., Li, X., Feng, G. and Christie, P. (2001). Mobilization of sparingly soluble inorganic phosphates by external mycelium of an arbuscular mycorrhizal fungus. Plant and Soil. 230: 279-285.

Zhang, Z., Zhang, J., Xu, G., Zhou, L. and Li, Y. (2019). Arbuscular mycorrhizal fungi improve the growth and drought tolerance of Zenia insignis seedlings under drought stress. New Forests. 50(4): 593-604. 